\title{
Research on How to Measure the Success of Smart Growth of a City
}

\author{
Yurui Peng \\ North China Electric Power University, Baoding 071000, China
}

739408170@qq.com

\begin{abstract}
In this paper, we construct an evaluation metric of sustainable development called 'Smart Growth Score' (SGS) combining with the 3E's and the ten principles of smart growth. This provides a clearer description of how successful a city develops smartly. We build a scoring model called "Smart Growth Score" (SGS) for measuring the success of the urban smart growth. This model is mainly based on AHP (Analytic Hierarchy Process), FAHP (Fuzzy Analytical Hierarchy Process) and PCA (Principal Component Analysis). We use the AHP to confirm the index and the evaluating factors and construct a metric for the weight of them. Then we quantify them by constructing a score and a ratio for each of them. Finally, we give evaluation to our model, followed by a brief remark about our work.
\end{abstract}

Key words: PCA; SGS; 3E’s; FAHP; AHP; constructing a score; develops smartly.

\section{INTRODUCTION}

The world is rapidly urbanized. By 2050, the population of the city is expected to reach $66 \%$ of the world's total population. [1] Along with the emergence and transformation of information technology such as Internet, mobile communication technology, Internet of things and cloud computing, life style of human society has undergone tremendous changes. Meanwhile, many problems such as climate change, environmental pollution, financial risk, food safety, urban management and public safety have hindered the development and progress of modern society. All countries in the world hope to improve the level of economic development, improve the efficiency of resource utilization, reduce environmental pollution and provide new ideas for urban management and development based on major breakthroughs in technology. [2].

\section{ESTABLISHING 'SGS' EVALUATION MODEL BASED ON ANALYTIC HIERARCHY PROCESS}

\section{Analytic Hierarchy Process.}

1) Construct the judgment matrix

i. Firstly, construct the initial judgment matrix A by comparing and analyzing the importance among each factor.

$$
\mathrm{A}=\left[\begin{array}{ccc}
a_{11} & \ldots & a_{1 n} \\
\vdots & \ddots & \vdots \\
a_{n 1} & \ldots & a_{n n}
\end{array}\right]
$$

Where:

$a_{i j}$ represents the importance of the line factor I relative to the $\mathrm{j}$ column factor.

ii. Then by normalizing the initial judgment matrix, we get the judgment matrix B: 


$$
\mathrm{B}=\left[\begin{array}{ccc}
\frac{a_{11}}{\sum_{1}^{n} a_{i 1}} & \cdots & \frac{a_{1 n}}{\sum_{1}^{n} a_{i n}} \\
\vdots & \ddots & \vdots \\
\frac{a_{n 1}}{\sum_{1}^{n} a_{i 1}} & \cdots & \frac{a_{n n}}{\sum_{1}^{n} a_{i n}}
\end{array}\right]
$$

iii. Then, add each factor in the same row. Finally, dividing the answer of the addition by $\mathrm{n}$ to give the weight vector $\mathrm{N}$.

$$
\mathrm{N}=\frac{1}{n}\left[\begin{array}{c}
\sum_{j=1}^{n}\left(\frac{a_{1 j}}{\sum_{1}^{n} a_{i j}}\right) \\
\vdots \\
\sum_{j=1}^{n}\left(\frac{a_{n j}}{\sum_{1}^{n} a_{i j}}\right)
\end{array}\right]
$$

2) Make consistency check on the judgment matrix.

i. Calculate the maximum judgment matrix eigenvalues.

$$
\lambda_{\max }=\frac{1}{n} \sum_{i=1}^{n} \frac{(A \omega)_{i}}{\omega_{i}}
$$

Where:

$\omega$ is the eigenvector of the judgement matrix A

ii. Calculate the consistency indicators of the judgment matrix A:

$$
\mathrm{CI}=\frac{\lambda_{\max }-n}{n-1}
$$

iii. Calculate the random consistency ratio of the judgment matrix:

$$
\mathrm{CR}=\frac{C I}{R I}
$$

Where:

$\mathrm{RI}$ is the mean random consistency index.

The value of RI are listed in Table 1 .

TABLE 1. The value of $R I$ [3]

\begin{tabular}{|c|c|c|c|c|c|c|c|c|c|}
\hline$n$ & 1 & 2 & 3 & 4 & 5 & 6 & 7 & 8 & 9 \\
\hline$R I$ & 0 & 0 & 0.58 & 0.9 & 1.12 & 1.24 & 1.32 & 1.41 & 1.45 \\
\hline
\end{tabular}

If $\mathrm{CR}<0.1$, then the inconsistent of $\mathrm{A}$ is in the allowable range. Therefore, we can use $\mathrm{N}$ as the weight vector.

3) Quantize the abstract parameters.

Taking $\mathrm{Gm}=5$ as the highest score of the abstract parameters, we can get the score of each parameter according to linear transformation.

$$
G_{i j}=\frac{1}{n} \sum_{k=1}^{n}\left(\frac{P_{k}}{P_{m k}} \times G_{m} \times R_{k}\right)
$$

Where:

$\mathrm{k}$ represents evaluation factor.

$P_{k}$ represents the quantitative indicator.

$P_{m k}$ represents the maximum of quantitative indicator.

$G_{i j}$ represents score of abstract parameter.

$R_{k}$ represents the radio of the current quantitative indicator to the previous one. 
Determine the Success Rate of smart growth according to the metric listed in Fig. 1:

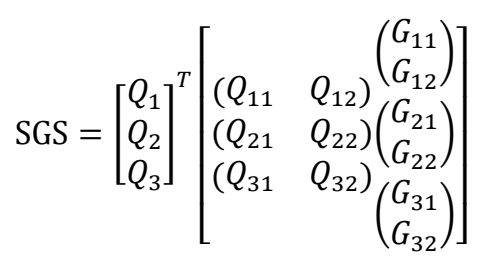

Where:

Q represents weight of abstract parameter

According to the three E's of sustainability and the 10 principles of smart growth, develop a metric to measure the success of smart growth of a city. The hierarchical model of smart growth of a city is as follows: [4].

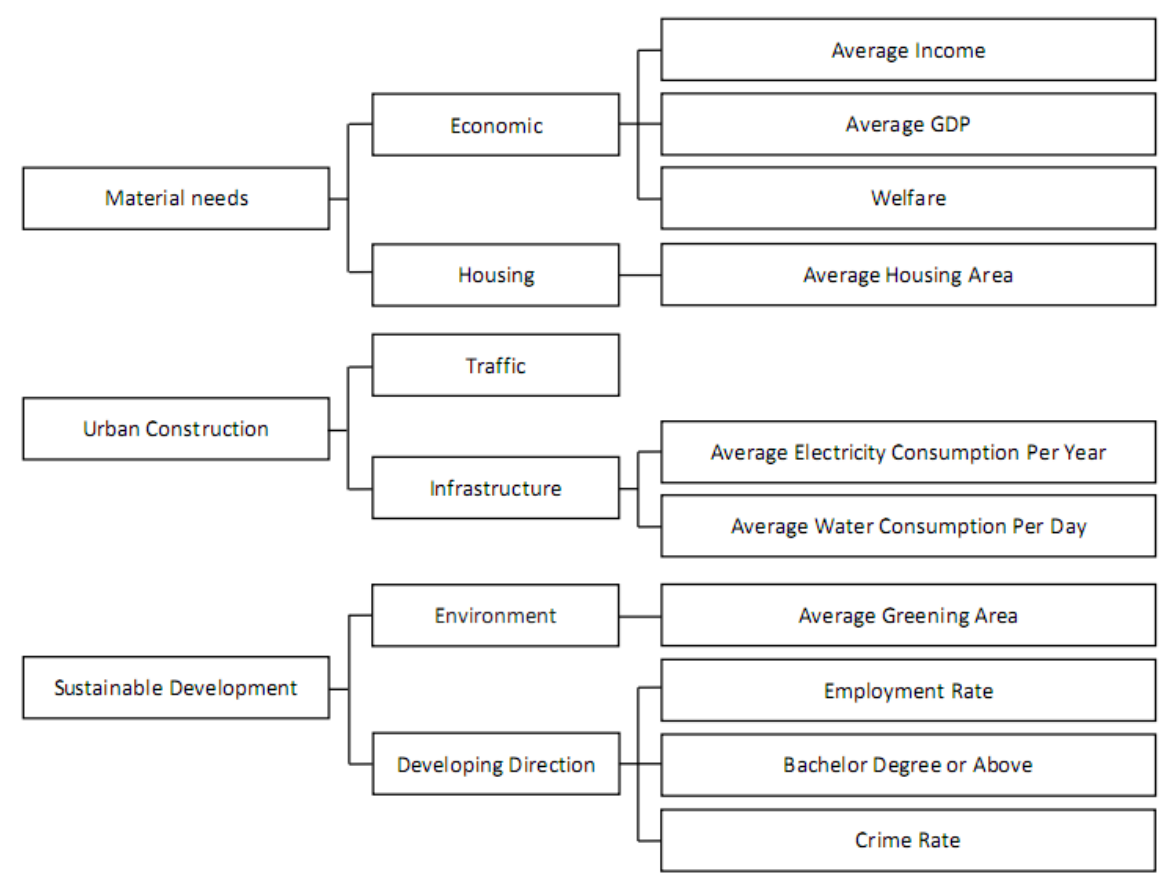

FIGURE 1. Hierarchical model of smart growth of a city.

\section{Model Testing}

Bergen is selected as the research object and its development plan is studied. Based on the proposed model, a quantitative analysis is made to evaluate the success of the smart growth in Bergen.

Bergen is a fair and inclusive city and everyone has equal opportunities. In terms of increasing employment, government allocate 15 million dollars in order to solve the problem of unemployment. Commissioner proposes that 7.5 million will be used to solve the problem of youth unemployment. [5]

Based on the above data, the one-level smart growth judgment metric is as follows:

TABLE 2. Judgment matrix of one-level smart growth

\begin{tabular}{|c|c|c|c|}
\hline Smart Growth & Material Needs & Urban Construction & Sustainable Development \\
\hline Material Needs & 1.00 & 1.33 & 1.50 \\
\hline Urban Construction & 0.75 & 1.00 & 0.85 \\
\hline Sustainable Development & 0.67 & 1.18 & 1.00 \\
\hline
\end{tabular}


TABLE 3. Normalized judgment matrix of one-level smart growth

\begin{tabular}{|c|c|c|c|}
\hline Smart Growth & Material Needs & Urban Construction & Sustainable Development \\
\hline Material Needs & 0.41 & 0.38 & 0.45 \\
\hline Urban Construction & 0.31 & 0.28 & 0.25 \\
\hline Sustainable Development & 0.28 & 0.34 & 0.30 \\
\hline
\end{tabular}

Finally, the eigenvector of the one-level metric we get is:

$$
\mathrm{N}=\left[\begin{array}{l}
P_{1} \\
P_{2} \\
P_{3}
\end{array}\right]=\left[\begin{array}{c}
0.42 \\
0.28 \\
0.3
\end{array}\right]
$$

Consistency checking the judgment matrix, based on Eq.4, Eq.5, Eq.6, we find that $\mathrm{CR}=0.005<0.1$. Therefore, $\mathrm{N}$ can be used as the weight vector.

Similarly, we also get the weight of the two-level indexes as follows:

$$
\begin{aligned}
& M_{1}=\left[\begin{array}{l}
Q_{11} \\
Q_{12}
\end{array}\right]=\left[\begin{array}{l}
0.58 \\
0.42
\end{array}\right] \\
& M_{2}=\left[\begin{array}{l}
Q_{21} \\
Q_{22}
\end{array}\right]=\left[\begin{array}{l}
0.6 \\
0.4
\end{array}\right] \\
& M_{3}=\left[\begin{array}{l}
Q_{31} \\
Q_{32}
\end{array}\right]=\left[\begin{array}{l}
0.72 \\
0.28
\end{array}\right]
\end{aligned}
$$

After consulting lots of literature, we obtain some date about Bergen as follows:

TABLE 4. Date about Bergen [6]

\begin{tabular}{|c|c|c|}
\hline & 2011 & 2016 \\
\hline GDP & 6.47 & 7.14 \\
\hline Welfare Proportion & $76 \%$ & $75.00 \%$ \\
\hline Per Capita Income & 40572 & 43350 \\
\hline Per Capita Housing Area & 108.4 & 113.0 \\
\hline Infrastructure Supporting & $69.12 \%$ & $71.20 \%$ \\
\hline Greening Rate & $56.50 \%$ & $58.00 \%$ \\
\hline Employment Rate & $66.80 \%$ & $67.30 \%$ \\
\hline Higher Education Rate & $32.80 \%$ & $33.15 \%$ \\
\hline Crime Rate & $1.50 \%$ & $4.50 \%$ \\
\hline
\end{tabular}

Then we calculate the success rate index SGS according to the model, based on Eq. 7 and Eq. 8 .

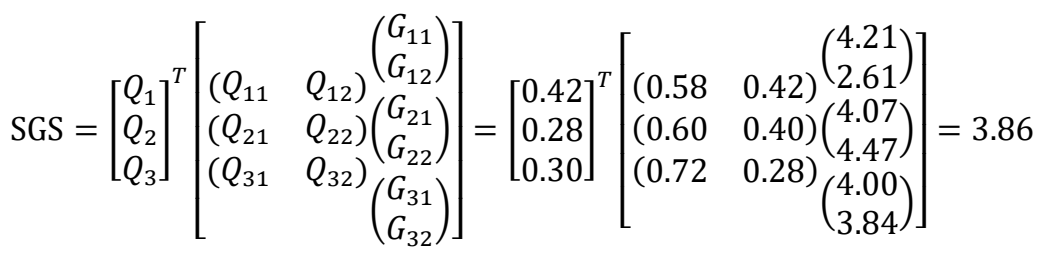




\section{CONCLUSION}

In the quantitative analysis, we quantify the degree of the success rate of urban smart growth with numerical SGS. The greater SGS is, the greater the degree of the success rate of urban intelligence growth is. Although Bergen is Norway's second-largest city, its policy efforts and investment is limited. The scale of various facilities to be improved and did not meet the degree of excellence.

\section{MODEL EVALUATION}

Evaluation model for the evaluation of urban intelligent growth model, both on the state of analysis and on the trend of analysis, making the evaluation more comprehensive.

Wide range of applications. In social life, the evaluation of a region or a system is more and more common. Because of the universality of our model, it can be applied to many other systems and make a more accurate evaluation for each system.

\section{REFERENCES}

1. World Urbanization Prospects [Z]. United Nations,2014.

2. Peng Du, Bin Xia, and Lei Yang: Science \& Technology Progress and Policy, Vol. 30 (2013) No.6, p.108. (In Chinese).

3. Arellano M, Bond S. "Some Tests of Specification for Panel Data: Monte Carlo Evidence and an Application to Employment Equations," Review of Economic studies, 1991.

4. Yuning Qi: Industrial Technology Innovation, Vol. 4 (2017) No.2, p.9. (In Chinese).

5. Information on https://www.bergen.kommune.no/.

6. Information on http://www.ssb.no/en/.

7. Lijiao Yin: Comprehensive Evaluation of Intelligent City Construction Level (MS., North China Electric Power University, China 2012), p.10. (In Chinese).

8. Xiaobo Cai: TROPICAL GEOGRAPHY, Vol. 30 (2010) No.1, p.84. (In Chinese).

9. Jingqi Zhang, Ping Sun, Xiujuan Ji and Ying Tang: CHINA POPULATION, RESOURCES AND ENVIRONMENT, Vol. 21 (2011) No.1, p.33. (In Chinese)

10. Jing Tan and Xu Chen: Economic Forum, Vol. 452 (2009) No.4, p.58. (In Chinese). 